
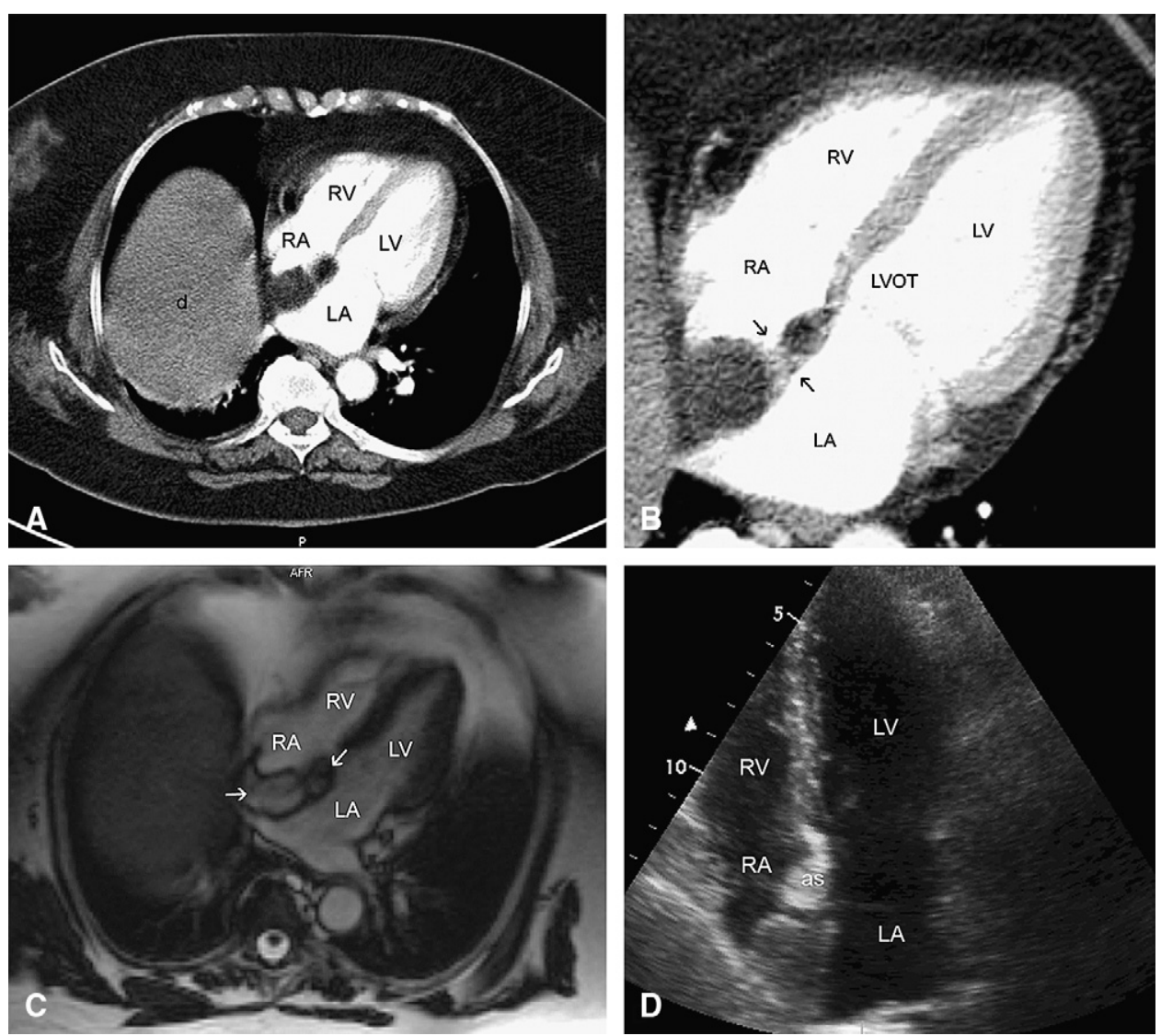

FIGURE 1. CT scans. $L A$, Left atrium; $R A$, right atrium; $L V$, left ventricle; $R V$, right ventricle; $L V O T$, $\mathrm{LV}$ outflow tract; $d$, diaphragm; $a s$, atrial septum.

\section{References}

1. Heyer CM, Kagel T, Lemburg SP, Bauer TT, Nicolas V. Lipomatous hypertrophy of the interatrial septum: a prospective study of incidence, imaging findings, and clinical symptoms. Chest. 2003;124:2068-73.

2. Nadra I, Dawson D, Schmitz SA, Punjabi PP, Nihoyannopoulos P. Lipomatous hypertrophy of the interatrial septum: a commonly misdiagnosed mass often leading to unnecessary cardiac surgery. Heart. 2004;90: e66.
3. Xanthos T, Giannakopoulos N, Papadimitriou L. Lipomatous hypertrophy of the interatrial septum: a pathological and clinical approach. Int J Cardiol. 2007;121:4-8.

4. Kindman LA, Wright A, Tye T, Seale W, Appleton C. Lipomatous hypertrophy of the interatrial septum: characterization by transesophageal and transthoracic echocardiography, magnetic resonance imaging, and computed tomography. J Am Soc Echocardiogr. 1988;1:450-4.

5. O'Connor S, Recavarren R, Nichols LC, Parwani AV. Lipomatous hypertrophy of the interatrial septum: an overview. Arch Pathol Lab Med. 2006;130:397-9.

\title{
Takotsubo cardiomyopathy after repair of ruptured abdominal aortic aneurysm
}

Yukio Umeda, MD, PhD, Yukihiro Matsuno, MD, PhD, Matsuhisa Imaizumi, MD, PhD, Yoshio Mori, MD, PhD, and

Hiroshi Takiya, MD, PhD, Gifu, Japan

From the Department of Cardiovascular Surgery, Gifu Prefectural General Medical Center, Gifu, Japan.

Received for publication March 10, 2008; accepted for publication March 16, 2008. Address for reprints: Yukio Umeda, MD, PhD, Department of Cardiovascular Surgery, Gifu Prefectural General Medical Center, 4 - 6 - 1 Noishiki, Gifu city, 5008717, Gifu, Japan (E-mail: yukioumeda@mvd.biglobe.ne.jp).

J Thorac Cardiovasc Surg 2009;137:e4-6

$0022-5223 / \$ 36.00$

Copyright (c) 2009 by The American Association for Thoracic Surgery doi: $10.1016 /$ j.jtcvs.2008.03.017
Takotsubo cardiomyopathy was reported by Dote and associates $^{1}$ in a Japanese patient who had peculiar wall motion abnormalities and a balloon-shaped left ventricle with normal coronary arteries. Although the precise mechanism of Takotsubo cardiomyopathy remains unclear, several possible mechanisms have been proposed, including multivessel epicardial coronary spasm, microvascular coronary spasm, and catecholamine-mediated toxicity. ${ }^{2}$ Recently, several 

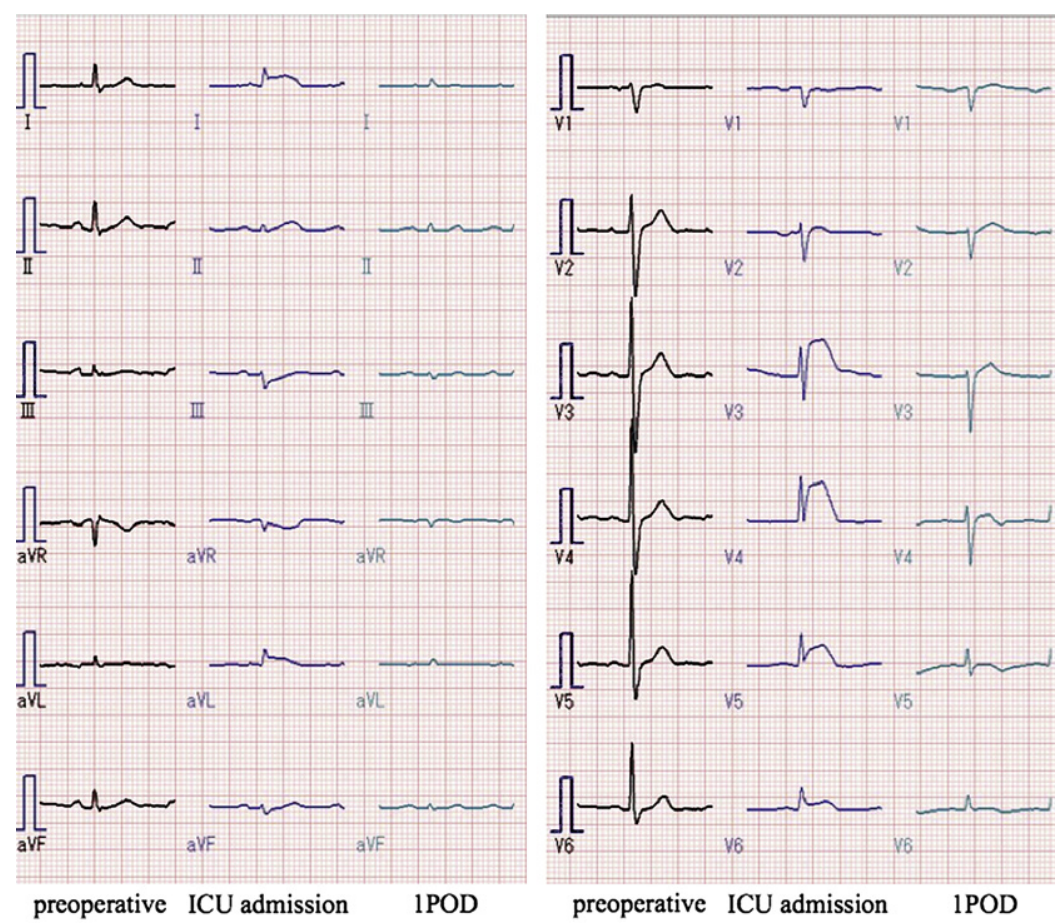

FIGURE 1. Electrocardiogram.

cases of postoperative Takotsubo cardiomyopathy were reported. ${ }^{3-5}$

We describe the first case of Takotsubo cardiomyopathy after repair of ruptured abdominal aortic aneurysm. Because this syndrome may mimic an acute myocardial infarction, early diagnosis and appropriate treatment are crucial.

\section{CLINICAL SUMMARY}

An 82-year-old woman was referred to our department for ruptured abdominal aortic aneurysm. The patient had no history or symptoms of coronary artery disease, and the preoperative electrocardiogram showed no abnormalities. An emergency operation involving typical repair of the abdominal aorta with a bifurcated vascular prosthesis was performed with the patient under general anesthesia. Intraoperatively, a large blood transfusion $(1680 \mathrm{~mL}$ of packed red cells, $960 \mathrm{~mL}$ of fresh frozen plasma, and 250 $\mathrm{mL}$ of platelet concentrate) and reinfusion of the autologous blood recovered by the blood salvage machine were required for massive bleeding from the aneurysm. No significant changes in the electrocardiogram were detected during the operation.

The patient was admitted to the intensive care unit (ICU) with continuous infusion of nicorandil and nitroglycerin plus respiratory support. A 12-lead electrocardiogram on admission to the ICU showed ST-segment elevation in leads $\mathrm{I}, \mathrm{aVL}$, and $\mathrm{V}_{3-6}$ (Figure 1). Then, transthoracic echocardiography was performed by a cardiologist. Although transthoracic echocardiography showed akinesia of the mid-to-distal portion of the left ventricular chamber, the creatine kinase MB fraction was within normal limits and the hemodynamic status of the patient was stable. The diagnosis of Takotsubo cardiomyopathy was made and careful observation was selected. A follow-up electrocardiogram performed 8 hours later showed normalization of ST-segment elevation. No significant changes in the electrocardiogram or clinical parameters were observed during further stay in the ICU. Coronary angiography performed on postoperative day 13 revealed a normal coronary artery. The postoperative course of the patient was uneventful.

\section{DISCUSSION}

Takotsubo cardiomyopathy is a recently described form of transient ventricular dysfunction that is not associated with coronary artery obstruction, although its clinical manifestations are often similar to those of myocardial infarction. ${ }^{1}$ This syndrome is possibly due to excessive catecholamine, and it is associated with emotional or physical stress. ${ }^{2}$ Several cases of Takotsubo cardiomyopathy associated with surgery or anesthesia have been reported previously. ${ }^{3-5}$ Complications of Takotsubo syndrome include left heart failure, cardiogenic shock in extreme cases, dynamic intraventricular obstruction with acute mitral regurgitation, ventricular arrhythmias, and left ventricular free wall rupture. However, this transient disorder can usually be managed by supportive therapy and the overall prognosis of this syndrome seems to be favorable. ${ }^{3}$ Therefore, early diagnosis and appropriate treatment are crucial. Emergency 
coronary angiography is critical to rule out the diagnosis of typical myocardial infarction and to allow for the arrival at the correct diagnosis of Takotsubo cardiomyopathy. On the other hand, emergency coronary angiography is more invasive for the patient undergoing emergency surgery. Especially in the patient who has a ruptured aortic aneurysm, oozing from the retroperitoneal small vessels injured by hematoma or surgical procedure is of concern because of the use of anticoagulants for catheterization. In our patient, despite a large blood transfusion including the platelet concentrates, platelet count on ICU admission was $6.0 \times 10^{4} / \mu \mathrm{L}$. Therefore, we initially obtained transthoracic echocardiography by a cardiologist. According to the typical findings of Takotsubo cardiomyopathy revealed by echocardiography, normal creatine kinase $\mathrm{MB}$ fraction, and stable hemodynamic status, we selected careful observation.

We routinely perform preoperative coronary angiography to assess the risk of perioperative myocardial infarction. Although preoperative intact coronary angiography is also meaningful to avoid needless or harmful coronary angiography in the perioperative period, as in the case with our patient, preoperative screening for heart disease is often limited to an electrocardiogram in emergency cases. However, in a certain situation, Takotsubo cardiomyopathy could be diagnosed by integration of clinical noninvasive modalities.

We described the first case of Takotsubo cardiomyopathy after ruptured abdominal aortic aneurysm repair. We considered that diagnosis of this syndrome could be and should be made without invasive coronary angiography in certain situations to avoid further complications.

\section{References}

1. Dote K, Sato H, Tateishi H, Uchida T, Ishihara M. Myocardial stunning due to simultaneous multivessel coronary spasms: a review of 5 cases. J Cardiol. 1991;21: 203-14.

2. Tsuchihashi K, Ueshima K, Uchida T, Oh-mura N, Kimura K, Owa M, et al. Transient left ventricular apical ballooning without coronary artery stenosis: a novel heart syndrome mimicking acute myocardial infarction. Angina PectorisMyocardial Infarction Investigations in Japan. J Am Coll Cardiol. 2001;38:11-8.

3. Lee HR, Hurst RT, Vargas HE. Transient left ventricular apical ballooning syndrome (Takotsubo cardiomyopathy) following orthotopic liver transplantation. Liver Transplant. 2007;13:1343-5.

4. Jabaudon M, Bonnin M, Bolandard F, Chanseaume S, Dauphin C, Bazin JE. Takotsubo syndrome during induction of general anaesthesia. Anaesthesia. 2007;62: 519-23.

5. Chun SG, Kwok V, Pang DK, Lau TK. Transient left ventricular apical ballooning syndrome (Takotsubo cardiomyopathy) as a complication of permanent pacemaker implantation. Int J Cardiol. 2007;117:e27-30.

\title{
Do statins delay the progression of aortic stenosis?
}

\author{
Hisato Takagi, MD, PhD, Norikazu Kawai, MD, and Takuya Umemoto, MD, PhD, Shizuoka, Japan
}

Calcific aortic stenosis (AS) is the most common form of valvular heart disease in the Western world, and the only established therapy for patients with severe symptomatic AS is surgical valve replacement. There are currently no effective disease-modifying treatments, and the possibility of halting the disease process would represent a therapeutic advance. ${ }^{1}$ Although some observational studies ${ }^{2-4}$ demonstrated that statins (hydroxymethylglutaryl-coenzyme A reductase inhibitors) delayed the progression of AS, a randomized controlled trial ${ }^{1}$ concluded that intensive lipid-lowering therapy with atorvastatin did not halt its progression. Furthermore, no meta-analysis of studies of statins for AS has been conducted to date. Therefore, the appropriate role of statins

From the Department of Cardiovascular Surgery, Shizuoka Medical Center, Shizuoka, Japan.

Received for publication March 4, 2008; accepted for publication March 14, 2008.

Address for reprints: Hisato Takagi, MD, PhD, Department of Cardiovascular Surgery,

Shizuoka Medical Center, 762-1 Nagasawa, Shimizu-cho, Sunto-gun, Shizuoka

411-8611, Japan (E-mail: kfgth973@ybb.ne.jp).

J Thorac Cardiovasc Surg 2009;137:e6-9

$0022-5223 / \$ 36.00$

Copyright (c) 2009 by The American Association for Thoracic Surgery doi:10.1016/j.jtcvs.2008.03.018 for AS remains unclear. We performed a meta-analysis of comparative studies of statins for the prevention of the progression of $\mathrm{AS}$.

\section{CLINICAL SUMMARY}

All comparative studies of statins versus control (no statins or placebo) for AS were identified using a 2-level search strategy. First, a public domain database (MEDLINE) was searched using a Web-based search engine (PubMed). Second, relevant studies were identified through a manual search of secondary sources, including references of initially identified articles and a search of reviews and commentaries. The MEDLINE database was searched from January of 1966 to January of 2008. MeSH keywords included "hydroxymethylglutaryl-CoA reductase inhibitors" and "aortic valve stenosis.' Studies considered for inclusion met the following criteria: The design was a comparative study, and the study population comprised patients with AS. Patients were assigned to statins versus control (no statins or placebo), and the main outcomes included annualized changes of echocardiographic characteristics. Data regarding detailed 